\title{
DISEMINASI PENGELOLAAN RTH PEMUKIMAN UNTUK MENINGKATKAN BIODIVERSITAS FLORA
}

Fabiola Baby Saroinsong ${ }^{1)}$, Josephus Innocentius Kalangi ${ }^{2}$

Universitas Sam Ratulangi, ${ }^{1,2)}$

\begin{abstract}
ABSTRAK
Beberapa masalah lingkungan di perkotaan yang sering ditemui adalah polusi udara, menurunnya infiltrasi air hujan, heat island effect, dan tidak kalah penting adalah menurunnya biodiversitas. Padahal RTH dengan biodiversitas flora yang tinggi menyediakan banyak fungsi, baik ekologi, ekonomi, estetika maupun amenity. Secara khusus di lingkungan mitra, permasalahan yang bisa diamati pada survey awal adalah adanya kecenderungan masyarakat menutupi halaman yang tersisa dengan perkerasan, penyeragaman dalam pemilihan dan penanaman RTH pemukiman, kurangnya pemahaman tentang fungsi RTH dan manfaat biodiversitas flora. Solusi yang ditawarkan adalah diseminasi RTH pemukiman yang meningkatkan biodiversitas flora, meningkatkan pengetahuan masyarakat tentang fungsi RTH, manfaat RTH dengan nilai biodiversitas flora yang tinggi, dan meningkatkan kemampuan masyarakat untuk melakukan pengelolaan RTH pemukiman dengan tindakan-tindakan praktis konservasi sehingga diharapkan dapat diaplikasikan dalam kehidupan mereka sehari-hari. Lokasi kegiatan pengabdian yaitu Kelurahan Winangun Dua Kota Manado, Sulawesi Utara dengan objek (khalayak sasaran) yaitu kelompok masyarakat Winangun Dua Lingkungan 1 dan Lingkungan 3. Tujuan PKM ini adalah mentransfer iptek pengelolaan ruang terbuka hijau (RTH) kawasan pemukiman, mencakup pemilihan dan pengkombinasian jenis-jenis tanaman, tindakan-tindakan praktis pengelolaan RTH, dan penerapan beberapa contoh desain RTH yang menarik tapi mudah diaplikasikan, estetis, produktif, tapi juga ekologis. Kegiatan PKM diharapkan dapat meningkatkan pendidikan lingkungan hidup masyarakat dan kualitas lingkungan.
\end{abstract}

Keywords: biodiversitas flora, konservasi, pekarangan, ruang terbuka hijau 


\section{PENDAhuluan}

Kota memiliki berbagai masalah lingkungan hidup yang yang berdampak pada masyarakat maupun lingkungan itu sendiri. Beberapa di antaranya adalah polusi udara, tanah dan air, menurunnya infiltrasi air hujan, permukaan air tanah, heat island effect, dan yang tidak kalah penting yaitu menurunnya biodiversitas. Tingginya penurunan biodiversitas flora dalam lanskap perkotaan sebagai akibat alih fungsi lahan dan ketidaktepatan pengelolaan SDA menjadi perhatian yang serius untuk upaya pelestarian dan perlindungan ekosistem (Bode et al., 2015; Brown, 2015).

Lokasi kedua mitra adalah Winangun

Dua Lingkugan 1 dan Lingkungan 3. Kondisi lingkungan mitra dapat dilihat pada Gambar 1 dan 2. Selain penurunan luasan ruang terbuka hijau (RTH) karena terdesak berbagai kepentingan penggunaan lahan, kecenderungan perluasan penutupan lahan dengan perkerasan, penyeragaman spesies meluas karena masyarakat memilih spesies dengan mengikuti trend, sekedar meniru

$\mathrm{RTH}$, di dalamnya tercakup RTH kawasan pemukiman, penting untuk kotakota berkelanjutan karena mengakomodasi aktivitas-aktivitas luar dan sangat besar berkontribusi pada kualitas hidup perkotaan dan kenyamanan manusia. Melalui transfer iptek yang tepat, masyarakat Kelurahan Winangun Dua Lingkungan 1 dan desain yang dianggap bagus, terbatasnya pilihan jenis pada penjual tanaman hias, atau juga dengan alasan memudahkan pemeliharaan. Hal-hal tersebut pada akhirnya mengancam biodiversitas flora (Reyers et. al., 2009; Kardan, 2015; Ahmadi, Sadeghi and Eskandarinezhad, 2016). Padahal RTH dengan biodiversitas flora yang tinggi menyediakan banyak fungsi ekologi, ekonomi, dan amenity yang meningkatkan kualitas lingkungan perkotaan seperti menyediakan makanan, menopang kehidupan satwa liar, lebih efektif menyaring udara dan mengurangi polusi udara, meredam kebisingan, meningkatkan infiltrasi air dan mengisi ulang air tanah, meningkatkan nilai estetika kota, meningkatkan kesehatan manusia, menciptakan naungan dan meningkatkan kenyamanan termal (Fuller, 2007; Dahmann, et al., 2010; Escobedo, Kroeger, and Wagner, 2011; Roy, Byrne and Pickering, 2012; Villeneuve et al., 2012; Babo, Saroinsong, Kalangi, 2017; Saroinsong, Kalangi, Babo, 2017).

Lingkungan 3 dilengkapi dengan pemahaman berkaitan pengelolaan RTH sehingga dapat berkontribusi dalam pengelolaan RTH pemukiman yang menunjang biodiversitas flora (Hasbullah, 2008; Dahmann, et al., 2010; Susilowati dan Nurni, 2013; Kardan, 2015). 


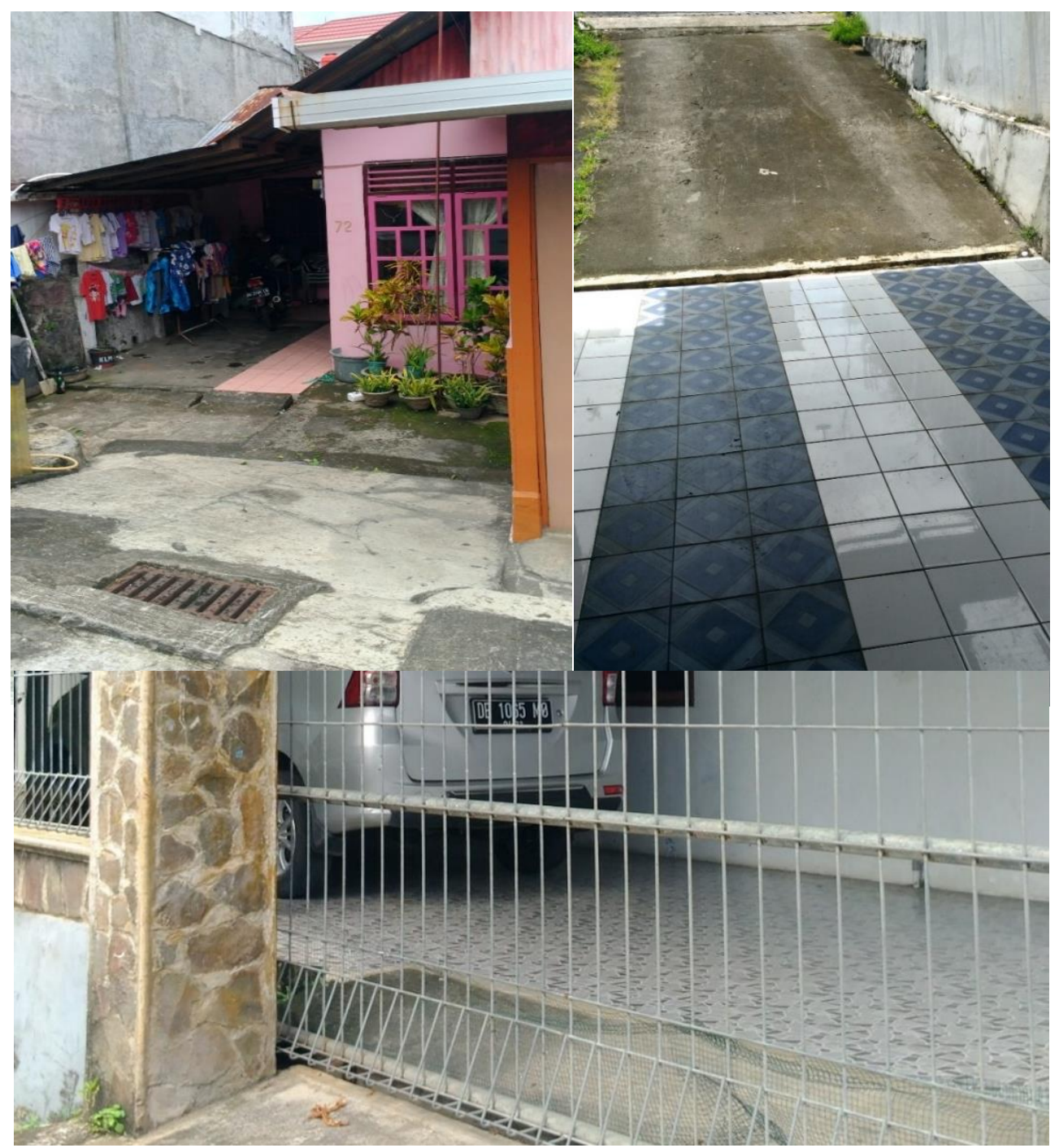

Gambar 1. RTH yang Terdesak oleh Perluasan Bangunan dan Perkerasan 


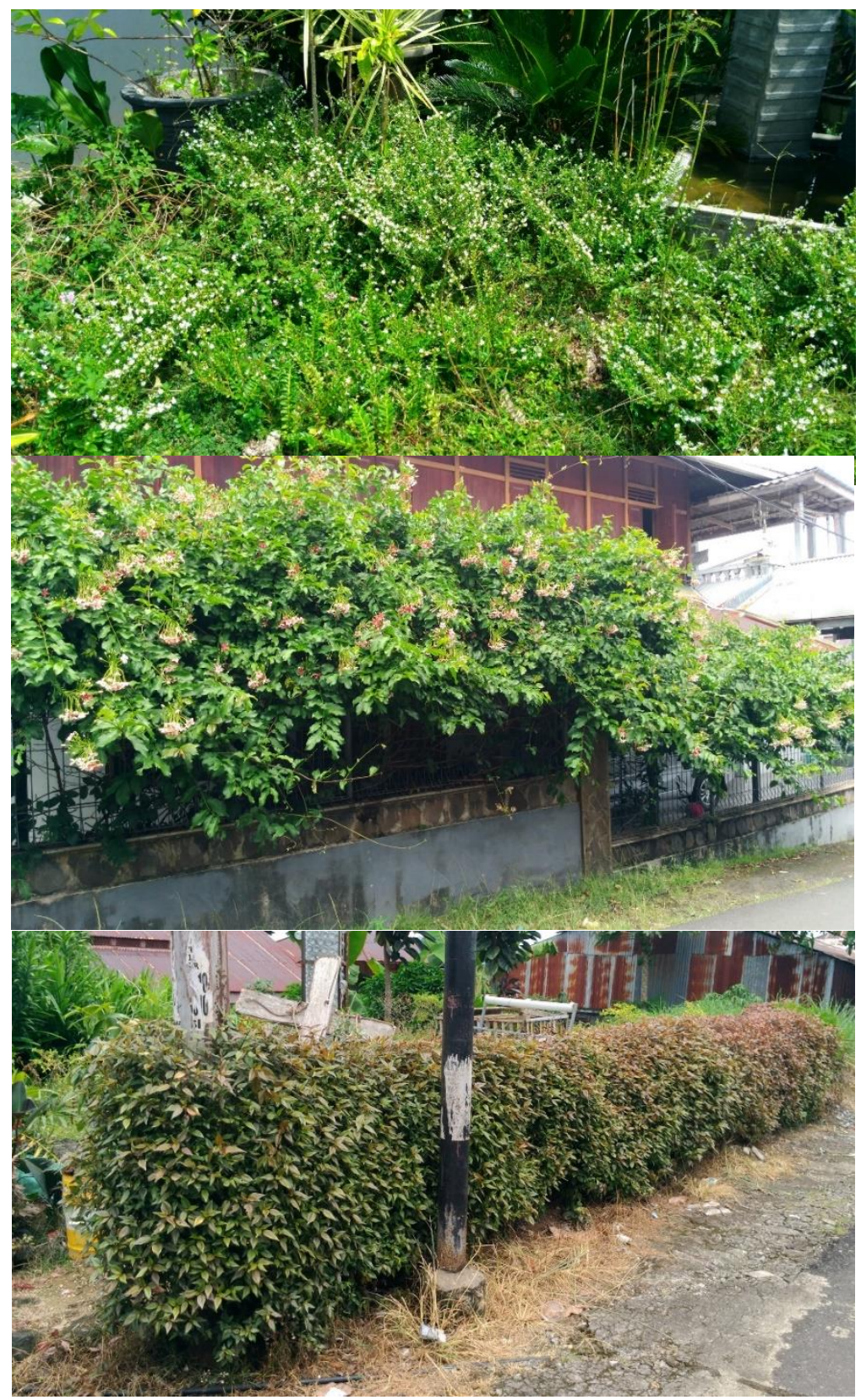

Gambar 2. Kecenderungan Penyeragaman Tanaman di RTH Pemukiman Winangun Dua Lingkungan 1 dan Lingkungan 3 
Secara khusus di lingkungan mitra, permasalahan yang bisa diamati pada survey awal adalah adanya kecenderungan masyarakat menutupi halaman yang tersisa dengan perkerasan, penyeragaman dalam pemilihan dan penanaman RTH, kurangnya pemahaman tentang fungsi RTH dan manfaat nilai biodiversitas. Solusi yang ditawarkan adalah meningkatkan pengetahuan masyarakat tentang fungsi RTH, manfaat RTH dengan nilai biodiversitas yang tinggi, dan meningkatkan kemampuan masyarakat untuk melakukan pengelolaan RTH pemukiman dengan tindakan-tindakan praktis konservasi sehingga diharapkan akan diaplikasikan dalam kehidupan mereka sehari-hari.

Tim Pengusul dan Mitra menyepakati bahwa inti persoalan yang akan diselesaikan selama pelaksanaan program IbM ini secara umum adalah bagaimana meningkatkan pengetahuan masyarakat tentang lingkungan dan apresiasi terhadap lingkungan, dan secara khusus adalah untuk meningkatkan kemampuan masyarakat untuk melakukan pengelolaan pekarangan dengan tindakantindakan praktis konservasi sehingga diharapkan akan diaplikasikan dalam kehidupan mereka sehari-hari. Pemilihan dan pengkombinasian jenis-jenis tanaman, tindakan-tindakan praktis pengelolaan $\mathrm{RTH}$, dan contoh-contoh desain RTH yang menarik tapi mudah dibuat akan disertakan dalam penyuluhan.

\section{METODE PELAKSANAAN}

Kegiatan secara keseluruhan diselesaikan dalam waktu delapan (8) bulan. Lokasi kegiatan adalah Kelurahan Winangun Dua Kecamatan Malalayang Provinsi Sulawesi Utara. Metode pelaksanaan kegiatan yaitu penyuluhan/penyadaran. Pelibatan peserta penyuluhan dilakukan sehingga materi pendidikan konservasi dapat lebih diserap. Pelaksanaan pengabdian dilakukan dalam beberapa kegiatan sebagai berikut.
1) Pengumpulan data berupa inventarisasi situasi lokasi pelaksanaan kegiatan, diperoleh dengan cara survey lokasi dan wawancara terhadap mitra.

2) Penyusunan program bersama mitra dan komunikasi program, sesuai permasalahan dan kebutuhan mitra.

3) Persiapan bahan penyuluhan dan demo.

4) Pelaksanaan kegiatan penyuluhan dan evaluasi.

5) Pembuatan laporan, penulisan artikel untuk publikasi ilmiah, serta melakukan presentasi dalam seminar ilmiah.

Koordinasi dan komunikasi yang baik dari Tim Pengusul dan Mitra dijaga dengan baik untuk kelancaran kerja sama.

\section{HASIL DAN PEMBAHASAN}

Vegetasi merupakan elemen Ruang Terbuka Hijau (RTH), baik berupa RTH alami maupun RTH binaan yang dibangun di lahan publik (tanah negara) maupun tanah non-publik. Pemilihan vegetasi RTH di area pemukiman disesuaikan dengan kondisi fisik lingkungan, nilai estetika dan arsitektur kota, tujuan penggunaan dan manfaat baik langsung maupun tidak langsung, serta preferensi warga kota. Dalam pemberian materi penyuluhan PKM ini, RTH pemukiman diarahkan untuk fungsi ekologis sebagai fungsi utama dan fungsi keindahan/arsitektur, sosial dan ekonomi sebagai fungsi penunjang, dengan menitikberatkan pada arti penting biodiversitas flora.

Dalam lanskap perkotaan, selain penurunan luasan ruang terbuka hijau (RTH) karena terdesak berbagai kepentingan penggunaan lahan, penyeragaman spesies meluas karena masyarakat memilih spesies dengan mengikuti trend, sekedar meniru desain yang dianggap bagus, terbatasnya pilihan jenis pada penjual tanaman hias, atau juga dengan alasan memudahkan pemeliharaan. Hal-hal tersebut pada akhirnya mengancam biodiversitas flora. 
PKM ini dimaksudkan untuk mentransfer iptek pengelolaan RTH pemukiman sehingga masyarakat dilengkapi pemahaman dan ketrampilan berkaitan pengelolaan RTH yang dapat berkontribusi dalam meningkatkan biodiversitas flora di lingkungan perkotaan.

Pengelolaan SDA dan lingkungan harus dilakukan secara komprehensif dan dalam skala yang besar. Kontribusi masyarakat sangat diperlukan. Karenanya adalah penting untuk melakukan pembekalan dan pengkayaan ilmu dan teknologi kepada masyarakat luas mengenai pengelolaan RTH untuk meningkatkan biodiversitas flora (Diaz, et al., 2007; Hasbullah, 2008; de Groot, 2009; Egoh, B., 2009; Reyers et al. 2009; Setyowati, et al. 2014; Kardan, 2015).

Solusi yang ditawarkan untuk menyelesaikan permasalahan mitra adalah:

1. Meningkatkan pengetahuan dan pemahaman kelompok masyarakat mengenai cara pengelolaan RTH sehingga selain produktif dan estetis, juga ekologis, dalam hal ini meningkatkan biodiversitas flora.

2. Meningkatkan ketrampilan kelompok masyarakat berkaitan beberapa aplikasi praktis teknik pengelolaan RTH yang memungkinkan untuk diterapkan di lingkungannya sendiri.

Target utama yang ingin dicapai adalah peningkatan pemahaman masyarakat. Dalam penyuluhan, komunikasi tidak hanya satu arah melainkan dua arah melalui dibangunnya diskusi mengetahui manajemen biodiversitas flora pada sistem pekarangan secara tepat dan aplikatif sesuai masyarakat setempat, dengan menggali manfaat RTH secara holistik menurut pemahaman masyarakat, serta keterkaitan jenis-jenis tanaman dengan atribut sosial, budaya, religi, ekonomi dan ekologi/konservasi. Deskripsi substansi pelaksanaan PKM ini dapat dilihat pada Gambar 3

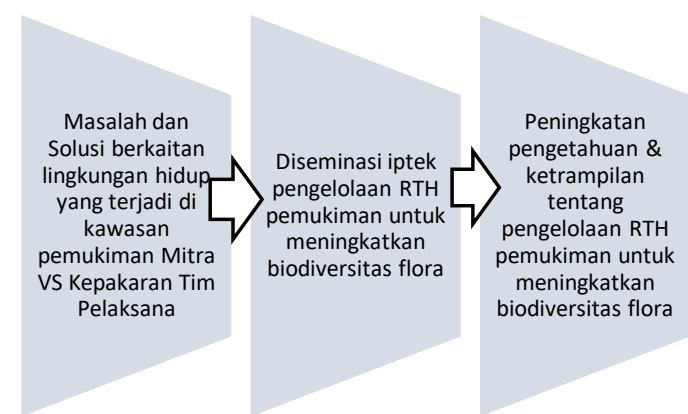

Gambar 3. Substansi Pelaksanaan PKM.

RTH permukiman merupakan unsur pembentuk dalam menciptakan elemen nature atau alam, dan society atau masyarakat (Susilowati dan Nurini, 2013). RTH sebagai unsur pembentuk nature dimaksudkan bahwa RTH perumahan permukiman mempunyai fungsi dalam mendukung kondisi perumahan permukiman salah satunya berfungsi ekologis. Sedangkan elemen society, RTH mempunyai salah satu fungsi sebagai media rekreasi dan interaksi social masyarakat. Lebih jauh menurut Marchese (2015), unitunit pengelolaan biodiversitas flora berbasis masyarakat pada sistem pekarangan dapat dikategorikan sebagai cerminan model sumberdaya hutan pada lingkungan pemukiman/pekarangan, sehingga dapat dikelola sebagai situs-situs atau spot sumberdaya hayati). Dengan demikian struktur dan komposisi tanaman di RTH area pemukiman, lebih terlihat lagi dalam pekarangan,: (1) menggambarkan kebutuhan masyarakat terhadap sumberdaya, (2) memungkinkan aneka spesies tumbuhan hutan mengalami domestikasi sehingga memperkaya biodiversitas flora pada lingkungan pekarangan, dan (3) merupakan sarana kepedulian masyarakat terhadap alam, terutama peningkatan kualitas lingkungan area pemukiman di perkotaan. 
Sistem pekarangan berperan strategis sebagai unit-unit ekologis yang memberikan manfaat jasa lingkungan terhadap masyarakat dan jasa ekosistem di sekitarnya (Njurumana, 2013). Unit-unit komunitas biodiversitas flora berbasis pekarangan di masyarakat perlu ditingkatkan pengelolaannya sebagai unitunit pengelolaan sumberdaya hayati berbasis masyarakat. Hal ini dapat dilakukan melalui : (1) penguatan nilai-nilai intrinsik berbasis sosial-budaya-religius yang mendukung pelestariannya, (2) penguatan kapasitas masyarakat dalam manajemen biodiversitas flora melalui pelatihan, penyuluhan dan pendampingan, (3) meningkatkan kapasitas sistem produksi dan produktivitasnya melalui diversifikasi produk secara efisien agar berdaya saing tinggi dan mengurangi kerusakannya, serta (4) dukungan kebijakan dan regulasi pemerintah daerah dalam mendorong pengelolaan unit-unit pekarangan berbasis masyarakat melalui sinergi pengembangannya dengan program pemerintah di masa depan.

\section{KESIMPULAN}

Sejak survey pelaksanaan IbM sampai pelaksanaannya, kedua mitra menunjukkan minat dan berperan aktif. Ada beberapa permintaan dan saran yang diajukan kepada Tim Pelaksana berkaitan dengan kelancaran pelaksanaan PKM. Tim Pelaksana menilai kerjasama yang baik dengan mitra mulai dari perencanaan program sampai pelaksanaannya adalah sangat penting dalam meningkatkan efisiensi dan efektifitas program kegiatan PKM dan penerimaan masyarakat.

\section{REFERENSI}

Ahmadi F., Sadeghi A. R. and Eskandarinezhad A. R. 2016. Ecological Quality Improvement of Urban Landscapes with Emphasis on Sustainable Development Principles Case Study: River of Darabad Valley, Tehran, Iran. European Journal of
Sustainable Development 5(3): 91102.

Babo, P., Saroinsong, F. B. Kalangi, J. I. 2017. Kenyamanan Termal Ruang Terbuka Hijau di Kampus UNSRAT Berdasarkan Persepsi Pengunjung. Cocos 1(2).

Bode, C., Saroinsong, F. B., Tasirin, J. S., Rombang, J. A. 2015. Analisis Perubahan Tutupan Lahan di Taman Hutan Raya Gunung Tumpa Menggunakan Sistem Informasi Geografis. Cocos 6(1).

Brown, R.D., Vanos, J., Kenny, N. and Lenzholzer, S. 2015. Designing urban parks that ameliorate the effects of climate change, Landscape and Urban Planning, 138, 118-131.

Dahmann, N., Wolch, J., Joassart-Marcelli, P., Reynolds, K., \& Jerrett, M. 2010. The Active city? Disparities in provision of urban public recreation resources. Healthand Place, 16(3), 431-445.

Escobedo, F. J., Kroeger, T., \& Wagner, J. E. 2011. Urban forests and pollution mitigation: Analyzing ecosystem services and disservices. Environmental Pollution,159(8), 2078-2087.

de Groot, R.S., Alkemade, R., Braat, L., Hein, L. \& Willemen, L. 2009. Challenges in integrating the concept of ecosystem services and values in landscape planning, management and decisionmaking.

Ecological Complexity, 7, 260-272

Diaz, S., Lavorel, S., De Bello, F., Que'tier, F., Grigulis, K. \& Robson, T.M. 2007 Incorporating plant functional diversity effects in ecosystem service assessments. Proceedings of the National Academy of Sciences, 104, 20684-20689. 
Egoh, B., Reyers, B., Rouget, M., Bode, M. and Richardson, D.M. 2009. Spatial congruence between biodiversity and ecosystem services in South Africa. Biological Conservation, 142, 553562.

Fuller, R. A., Irvine, K. N., Devine-Wright, P., Warren, P. H., \& Gaston, K. J. 2007. Psychological benefits of green space increase with biodiversity. Biology Letters, 3, 390-394.

Honjo, T. 2009. Thermal Comfort and Outdoor Environment. Global Environmental Research 13: 43-47.

Hasbullah, H. 2008. Pendidikan Konservasi untuk Orang Dewasa. Tropika 13.

Kardan, O. 2015. Neighborhood Greenspace and Health in a Large Urban Center. International Journal of Environmental Health Research 15: 319-337.

Marchese, C. 2015. Biodiversity Hotspots: A Shortcut for a More Complicated Concept. Global Ecology and Conservation, 3, 297-309.

Njurumana, G. N. 2015. Masyarakat Desa dan Manajemen Biodiversitas Flora pada Sistem Pekarangan di Kabupaten Sumba Tengah. Jurnal Penelitian Kehutanan Wallacea Vol. 5(1): 25-36.

Rahman, F., Kalangi, J. I., Saroinsong, F. B. 2018. Analisis Kebutuhan Luasan Ruang Terbuka Hijau Kota Manado Berdasarkan Fungsi Penyedia Oksigen. Cocos

Reyers, B.,O'Farrell, P.J., Cowling,R.M., Egoh, B.N.,Maitre, D.C.L. and Vlok, J.H.J. 2009 Ecosystem services, landcover change, and stakeholders: finding a sustainable foothold for a semiarid biodiversity hotspot. Ecology and Society, 14, 38 [http://www.ecologyandsociety.org/vo 114/iss1/art38].
Sasaoka, M and Laumonier, Y. 2012. Suitability of Local Resource Management Practices Based on Supernatural Enforcement Mechanisms in the Local Socialcultural Context. Ecology and Society 17(4):

http://www.ecologyandsociety.org/ vol17/iss4/art6/

Saroinsong, F. B., Kalangi, J. I., 2016. Teknik Pengelolaan Sumber Daya Alam untuk Konservasi di Area Pemukiman. Jurnal Abdimas Vol. 9(1).

Saroinsong, F. B., Kalangi, J. I., Babo, P. 2017. Redesain Ruang Terbuka Hijau Kampus UNSRAT berdasarkan Evaluasi Kenyamanan Termal dengan Indeks DISC. Eugenia Vol. 23(2):6275 .

Setyowati, D. L., Sunarko, Rudatin, Sedyawaati S. M. R. 2014. Pendidikan Lingkungan Hidup. Universitas Negeri Semarang

Susilowati, I. dan Nurini, 2013. Konsep Pengembangan Ruang Terbuka Hijau (RTH) pada Pemukiman Kepadatan Tinggi. Jurnal Pembangunan Wilayah dan Kota Vol. 9(4): 429-438 